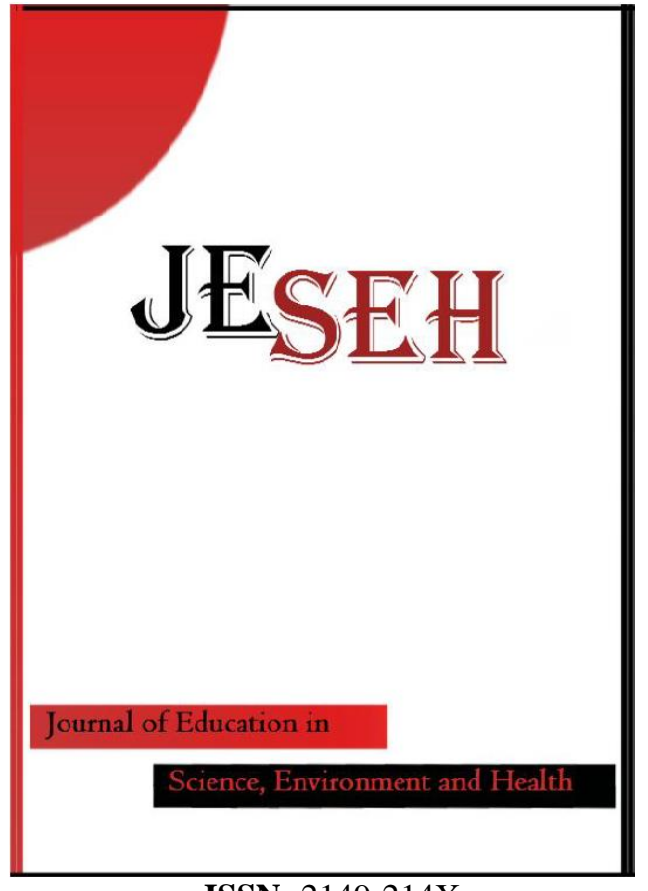

ISSN: $2149-214 \mathrm{X}$

\section{Journal of Education in Science,} Environment and Health

www.jeseh.net

Understanding and Assessing STEM Teachers' Use of IBL to Address Achievement-Related Diversity: A Case Study from Turkey

Gokhan Kaya ${ }^{1}$, Metin Sardag ${ }^{2}$

${ }^{1}$ Kastamonu University

${ }^{2}$ Van Yuzuncu Yil University

To cite this article:

Kaya, G. \& Sardag, M. (2021). Understanding and assessing STEM teachers' use of IBL to address achievement-related diversity: A case study from Turkey. Journal of Education in Science, Environment and Health (JESEH), 7(4), 283-295. https://doi.org/10.21891/ jeseh.962465

This article may be used for research, teaching, and private study purposes.

Any substantial or systematic reproduction, redistribution, reselling, loan, sub-licensing, systematic supply, or distribution in any form to anyone is expressly forbidden.

Authors alone are responsible for the contents of their articles. The journal owns the copyright of the articles.

The publisher shall not be liable for any loss, actions, claims, proceedings, demand, or costs or damages whatsoever or howsoever caused arising directly or indirectly in connection with or arising out of the use of the research material. 


\title{
Understanding and Assessing STEM Teachers' Use of IBL to Address Achievement-Related Diversity: A Case Study from Turkey
}

\author{
Gokhan Kaya, Metin Sardag
}

\begin{tabular}{|c|c|}
\hline Article Info & Abstract \\
\hline Article History & This study investigates how STEM teachers use inquiry-based learning (IBL) to \\
\hline $\begin{array}{l}\text { Published: } \\
01 \text { October } 2021\end{array}$ & $\begin{array}{l}\text { collected from three teachers who participated in a long-term in-service teacher } \\
\text { training program. Teachers' views were elicited through interviews, in-class }\end{array}$ \\
\hline $\begin{array}{l}\text { Received: } \\
\text { 02 January } 2021\end{array}$ & $\begin{array}{l}\text { observation, and evaluation forms. The data obtained were used in a narrative } \\
\text { structure to create a detailed case study of each teacher and compare them. It has } \\
\text { been determined that some strategies emphasize the diversity of success in IBL }\end{array}$ \\
\hline Acce & activities stand out more. Although these strategies are different, they enable IBL \\
\hline 23 May 2021 & $\begin{array}{l}\text { to progress in regularly and enable them to address the diversity of success in the } \\
\text { classroom. The lack of a wide variety of strategies used by teachers can be seen }\end{array}$ \\
\hline Keywords & $\begin{array}{l}\text { as one of the crucial problems in case studies. In particular, the use of methods } \\
\text { that will lead to better use of time in the classroom by using out of group work }\end{array}$ \\
\hline Inclusive education & and evaluating them in terms of successful diversity may appear to be an \\
\hline $\begin{array}{l}\text { STEM education } \\
\text { Inquiry based learning }\end{array}$ & nent in terms of achieving the desired goals. \\
\hline
\end{tabular}

\section{Introduction}

Classroom contexts are complex and diverse in terms of students' educational and cultural backgrounds, accessible resources, school culture, structure and size of classes. These are some of the factors that lead to the emergence of diversity in classes and level differences between student achievements (Chin \& Chia, 2006, Meijier, 2010). This complex and diverse nature of classes both requires proper management and teaching strategies as well as an effective learning process. These situations reveal the 'inclusive education approach.' Inclusive education aims to reduce the barriers to learning and participation for all students, not only for those with disabilities or who are classified as 'those with special educational needs' (Booth \& Ainscow, 2002). It is essential to ensure that every child and young person has access to, participation and regular use of inclusive education (EC, 2015). This situation makes it imperative for teachers to recognize and use diversity in the classroom.

Diversity and inclusive education studies in the classroom have been carried out for many different purposes in the field for many years, and there has been a growing interest in diversity research in science and mathematics classrooms (e.g. Lan \& de Oliveira, 2019; Nasir \& Cobb, 2006; Ramnarain, 2019; Ryu, 2019). The classroom is a very complicated social and institutional place where one teacher endeavours to interact with lots of students, maybe 30-40, to support them. There is unavoidable heterogeneity in terms of talking and thinking (Mortimer et al., 2012) as well as achievement. For achievement, teachers must consider that students' starting points and academic levels are different (Booth \& Ainscow, 2002, EC, 2015; Larina \& Markina, 2019). It is also emphasized that responding to the students' needs by considering their different starting points is a generic competence that teachers should gain in contemporary teacher training programs (Gonzalez \& Wagenaar, 2003; Starcic, 2010). It has been made clear that the interest comes from the growing diversity of classes in a globalizing world, and that the reports of the No Child Left Behind (U.S. Department of Education, 2002) and the European Commission on Progress towards Education and Training (2011, 2013 and 2015) are the responsibility of all education stakeholders, such as science and mathematics teachers.

Despite the reform movements in the field of science education to support equity and to try to close gaps in achievement, it is seen that there is a failure to reliably respond to the diversity of the student population (OECD, 2014). Programme for International Student Assessment (PISA) reports can be presented as evidence of this failure. For example, the PISA 2018 report (OECD, 2019) points out that a significant part of students, 24\% of 15 -year-old students in mathematics and $22 \%$ of the students in science, do not attain the necessary competence levels in these subjects in OECD countries. The EU commission's 2015 Education and Training Monitor showing that $22 \%$ of the 15 -year-olds are underachievers in mathematics and $17 \%$ in science. 
Inquiry-Based Learning (IBL) has positive effects on the acquisition of knowledge, conceptual understanding, and overcoming misconceptions and is thus a possible solution that can eliminate this adverse situation (Gormally et al., 2009). Additionally, according to Miles and Ainscow (2010), IBL practices are considered effective in addressing the diversity in classes. Brown (2017) also emphasized that IBL is a suitable approach to account for diverse student characteristics. The success and role of IBL in addressing diversity related to success have been emphasized in many studies. For example, Wilson et al. (2010) examined the effectiveness of inquiry-based materials and teaching and achievement gaps by various demographic variables such as gender, race/ethnicity, and socioeconomic status in terms of providing equitable opportunities to learn. Consequently, they point out that students can actively work on scientific problems based on their abilities and backgrounds in IBL classes. Therefore, the students will beneficially improve their skills and understanding compared to more prevalent science teaching. Additionally, it has been shown that it supports all students in terms of success. In the synthesis of IBL studies in Minner et al. (2010), the applications based on an inquiry led to a better understanding of scientific content regardless of students' ethnicity, gender and social-economic status, and $51 \%$ of the studies examined had a positive effect on students' science learning. Amaral et al. (2002) emphasize that IBL positively affects students' motivation and attitudes, while according to Gormally et al. (2009) it increases their self-esteem towards science lessons. In this way, IBL practices support all students whether they are at different levels or not, in terms of characteristics such as success, motivation, belief and attitude. Colburn (2000) places much responsibility for the success of IBL on the teacher, by emphasizing that teachers are the central decision-makers in terms how an inquiry approach is construed and adapted in the classroom. In another study, Larina and Markina (2019) categorized teachers' views on diversity and those who adopted the inclusive model sharply criticized the idea of dividing students into "strong" and "weak" groups within or between classes. From their point of view, such a classification renders the classroom's diversity inefficient for proper use. For them diversity and individuality are the principles of the inclusive model and are seen as models for educating everyone rather than excluding or stigmatizing "weak" students.

Successful use of IBL for diversity in classroom success is possible, with teachers successfully applying it in their classroom, as it emphasized the reports of the European Commission (EC, 2015). In this context, the Supporting Mathematics and Science Teachers in Addressing Diversity and Promoting Fundamental Values (MaSDiV) project that this study forms part of, is a study to develop modules for an inclusive science and mathematics education across Europe. The project was carried out using the IBL approach, which is often emphasized in the literature, to make the diversity of STEM teachers a positive part of science and mathematics lessons. According to the MaSDiV approach, inclusive mathematics and science education includes access for diverse learners in inquiry-based learning (IBL), using contexts to promote fundamental values and attention to diverse cultural backgrounds. Starting from this context, this study of IBL to support diversity in the classes of STEM teachers in Turkey attempts to understand how they use it. In this way, it will help us understand how inclusive mathematics and science teaching in schools are handled, used, and encountered by teachers. The research seeks answers to the questions are given below;

- How do lower secondary STEM teachers use IBL to address achievement-related diversity in Turkey?

- What do the teachers face the key challenges with and use as enabling strategies for effective classroom practices to address achievement-related diversity?

\section{National Context and Diversity of Turkey}

Subdivide text into unnumbered sections, using short, meaningful sub-headings. Please do not use numbered headings. Please limit heading use to three levels. Please use 12-point bold for first-level headings, 10-point bold for second-level headings, and 10-point italics for third -level headings with an initial capital letter for any proper nouns. Leave one blank line after each heading and two blank lines before each heading. (Exception: leave one line between consecutive headings.) Please margin all headings to the left.

Subdivide text into unnumbered sections, using short, meaningful sub-headings. Please do not use numbered headings. Please limit heading use to three levels. Please use 12-point bold for first-level headings, 10-point bold for second-level headings, and 10-point italics for third -level headings with an initial capital letter for any proper nouns. Leave one blank line after each heading and two blank lines before each heading. (Exception: leave one line between consecutive headings.) Please margin all headings to the left.

There are lots of factors of diversity in lower secondary schools in Turkey: language, religion, ethnic, achievement-related and ability diversity, which mean that students are gifted, and have cultural and 
socioeconomic diversity (ERG, 2018; TEDMEM, 2019; Eurydice, 2019). For example, OECD treats socioeconomic status in four parts namely the lower quarter, second quarter, third quarter, and an upper quarter in Turkey (Y1ldirım et al., 2013). Besides, there are students at all level in mathematics and science literacy in 2015 (Taş et al., 2016). Additionally, the numbers of the ten main groups of foreigners who are not refugees residing in Turkey in 2018 are 104,444 (Iraq), 99,463 (Syria), 67,522 (Turkmenistan), 65,027 (Azerbaijani), 44,313 (Iran), 39,283 (Afghanistan), 36,507 (Russia), 34,727 (Uzbekistan), 25,784 (Egypt), 25,645 (Kirghizstan) (Republic of Turkey Ministry of Interior Directorate General of Migration Management, 2019).

Science teaching curricula for lower secondary schools have aspects for IBL for nearly the last 15 years in Turkey (MoNE, 2005; 2018). It is seen that every unit in the science curriculum contains acquisitions related to it. Besides, textbooks include lots of inquiry-based activities (Kaya \& Y1lmaz, 2016). However, these activities are mostly confirmation and structured inquiry activities. The curriculum structure is established so that students may bring their daily life experiences into classrooms and, conversely, can take their school experiences out. Research shows that teachers in the classroom cannot fully implement these ideas in the program (Tüysüz \& Aydın, 2009). Although teachers are generally aware of the program's understanding and proposed activities, it is seen that this is not reflected in the classroom practices. The fact that the teachers do not have enough information about the new methods and their use in the application process, the inadequacy of the existing infrastructure (lack of equipment, crowd classes) are expressed as the reasons why the activities and understanding in the program cannot be fully implemented (Doğan, 2010). Science teachers are expected to improve students' reasoning skills and scientific thinking habits using socio-scientific issues in the new science curriculum (MoNE, 2018). Using contexts in IBL provides opportunity to teachers for accomplish to improve these skills.

\section{Method}

\section{Research Model}

The study was carried out using the case study design, which is one of the qualitative research approaches. Case studies involve an in-depth investigation of one or more than one case (Stake, 1995). Creswell (2009) describes a case study as an in-depth description of a case or multiple cases and its analysis. In the present study, IBL using STEM teachers to address achievement-related diversity was taken as the case. To conduct an in-depth analysis of this case, teachers' experiences and opinions were used. The whole participants' context handles within their settings as holistic case studies (Yin, 2009), and these compare as multiple case studies in this study. For that reason, the study was designed as a holistic multiple case design study. In this design, every participant is handled as a case in their own context, and then the cross-case analysis drawn on as a single unit of analysis (Yin, 2009).

\section{Participants}

All participants were members of an Erasmus+ project called MaSDiV, and the participant selection considered some criteria. These included joining all meetings, filling the evaluation form following the module homework, and obtaining in-class data (short clips, photos, students' worksheets). Besides that, the reinforcement contribution during the Continuous Professional Development (CPD) course is another selection criterion for the case studies. In line with these criteria, we investigate teachers' evaluation forms, classroom data, and faceto-face discussion in all CPD courses. At the end of this process, we chose nine teachers (5 science, 4 mathematics) from two different rural cities in Turkey. The researchers interviewed them using the semistructured interview protocol. The protocol consists of three dimensions: teachers' knowledge and experiences concerning IBL, their understanding for the role and use of contexts in science and mathematics teaching, and their experiences through the CPD. After that, three of the teachers were selected for the national case study report for this paper. The efficiency of the interviews and class observations and the fact that they provided us with a thick description for creating the case study reports have been considered in this selection. The detailed descriptions about the participants are given below to fully understand the teachers' background, school settings, and relation to the project. Besides that, the given information could provide clarity of comparison of their cases. Classroom research in general and especially data recordings are especially of ethical character. This study follows the Turkish Research Council's most recent recommendations for scientific research and publication ethics regulations (2012) in collecting and handling data. All teachers and caregivers were informed about the right to terminate their participation at any phase of the research process without giving any reasons. Before the study, the teachers and parents were asked to sign the informed consent form to participate in the 
study. Concerning all ethical issues, a university IRB committee approved all data collection and analyzing processes.

\section{Selma}

Selma is a mathematics teacher and has eight years of teaching experience and has worked for one year in the school where she carried out implements our project studies. One of her essential goals is to educate responsible individuals who respect the fundamental values of society. Selma experienced inquiry-based learning, context, and cultural diversity in the CPD course firstly.

There are 37 teachers (five science, six mathematics) and nearly 600 students in the school. Each classroom includes between 30 and 35 students who are in a wide range of academic achievement diversity. For example, in the same class, some students have faced problems related to the four arithmetic operations, while some have good exam scores at the lower secondary school level. She also mentioned that parents have nearly same socioeconomic status, and they are not sufficiently concerned with the students' education properly. For this reason, she pointed out that the education of the student is limited to school only.

\section{Bülent}

He is a science teacher and has four years' teaching experience as well as has worked for two years in the school intervention was carried out. There are 69 teachers (ten science, ten mathematics) and nearly 1700 students. The students have been selected via academic average obtained at the primary school level to participate in the school. The teachers focus on national exam success in terms of academic achievement. Nearly 40 students at the school achieve high-level scores from the national college exam in every year. There are the diversities of socioeconomic, religion, academic and student past experiences in the school.

The teacher has some experiences with inquiry-based learning. These come from in-services training programs related to STEM education and problem-based learning. However, he first experienced the contexts for science and mathematics subjects and the relationship between them and IBL during CPD.

\section{Ceren}

Ceren is a science teacher who has three years of experience and has just started her professional career. Her current school where she began teaching is a village school. Since it is a village school, it has inadequate facilities in terms of existing materials and laboratory equipment. The school serves as a primary and secondary school, and there are 55 students at the secondary level. The total number of teachers is ten when primary and secondary schools are added together. Ceren is the only science teacher in the school.

When Ceren evaluates the student's potential in the school, the students' academic level and their motivation towards the courses are high. In terms of diversity in the school, cultural, economic, and success can be considered to be diversity. The students come to school from a few different villages, so this situation creates cultural diversity. At the same time, Ceren emphasizes that cultural diversity, which includes different mother tongues and arises due to students being from other regions of Turkey, is true for most students and teachers. This leads to teachers and students sometimes having difficulty in understanding each other. In terms of success, the success of the student in school varies greatly. The teacher attributes this situation to the constant teacher's change at the primary school level and emphasizes that it causes children's low reading skills. It is stated that students who change teachers too many times at the primary school level are weaker in reading skills, but students with less teacher exchange are better in this subject.

Ceren generally has contemporary views in terms of the inquiry-based learning approach. She sees the inquirybased learning approach as "an approach that engages students to more thinking, allowing them to think and take the foundation of everyday life." Besides, under the teacher's guidance, it is emphasized that it is appropriate for students to conduct research and manage the process in a particular framework. She has some experiences that come from the undergraduate and postgraduate level related to IBL. She mentioned that she was educated to prepare IBL-based science lesson plans at the undergraduate level. 


\section{Data Sources}

Multiple data sources were used in the study process (see Table 1). The interview transcriptions and classroom observations are the primary evidence to construct the case study report. Moreover, evaluation forms about classroom implementations of the teachers are drawn on as evidence.

Table 1. Data sources

\begin{tabular}{|c|c|c|}
\hline Data sources & Focus & Details \\
\hline Interviews (after the CPD) & $\begin{array}{l}\text { Memories and reflection on thei } \\
\text { classroom implementation an } \\
\text { experiences related to IBL an } \\
\text { achievement-related diversity }\end{array}$ & 124 min audio recordings \\
\hline $\begin{array}{l}\text { Video recordings (during the } I B L \\
\text { lesson activities) }\end{array}$ & $\begin{array}{l}\text { Indicator of teacher focus on diversity } \\
\text { or facilities to draw on a diversity of } \\
\text { the classroom }\end{array}$ & $\begin{array}{l}\text { Five classroom hours audio-video } \\
\text { recordings from the classroom. }\end{array}$ \\
\hline $\begin{array}{l}\text { Evaluation forms (related to class } \\
\text { implementation) }\end{array}$ & $\begin{array}{l}\text { These were used as a tool to self- } \\
\text { reflection of teachers' implementation. }\end{array}$ & $\begin{array}{l}\text { The forms were filled by teachers } \\
\text { following their own IBL lessons. }\end{array}$ \\
\hline
\end{tabular}

We used three of them for each of the participants. Additionally, the Rope Activity, one of the MaSDiV project products (cf. MaSDiV, 2020) and Energy Resources and The Mars activities developed by teachers during teacher training, were used in the research. Energy Resources is an activity with a socio-scientific context in which the issue of whether the thermal power plants are installed or not is discussed, based on the positive and negative effects. The event was planned and implemented to research small groups. Students decide based on large and small group discussions from group interaction and individual thoughts based on research data. In the process, students make judgments by presenting arguments about whether power plants should be established considering their own culture and different cultures according to the positive and negative results of their establishment. Besides, the groups collect or develop arguments to support the view they advocate, generate ideas to raise social awareness (campaigns, symposia, etc.) and implement them. The Mars task is an IBL activity based on the research question: 'is there life in space?' In this activity, students work on the possibilities of living on Mars, how they could adapt to the presence of people on Earth if there were life, how to establish a social structure there and what could be the variables to consider. Through the activity, each group chooses a different research question and collects data about that question and tries to explain the context.

\section{Data Analysis}

The data obtained from different sources in the study were examined. The data analysis process consists of examining, coding, searching link of different sources. The whole process, as Merriam (1988) mentioned, is ongoing, recursive, and dynamic. In the first stage of data analysis, examining was done to reveal coding criteria for teachers' course records, interview records and other documents, in line with the purpose of the study and the diversity of the teacher's guidance. Then, coding was done using the criteria and by comparing these codings, it tried to identify common supporting structures in different sources. Finally, narrative case studies were created by bringing together analyses from different sources of data. Finally, by comparing case studies created independently of each other, common points about how IBL was used by teachers to support all students in the class and problems encountered were explained.

To ensure reliability and accountability, triangulation was attempted using multiple data sources (Patton, 1990). Also, classroom observations and interview transcripts were undertaken to increase accountability directly to presentations. Another essential concept is transferability (Yıldırım \& Şimşek, 2016). To transfer qualitative study results in similar situations, the research process and findings have been explained in detail. The concept of consistency comes to the fore to make qualitative data reliable (Lincoln \& Guba, 1986).

The qualitative data in this study were provided by the authors of this research observing the study group in pairs and reaching a conclusion by discussing and comparing the observation notes. As stated in the data analysis section, when the rater compliance ratios $(77 \%$ and $75 \%)$ are taken into consideration, the data obtained are seen to be reliable. Finally, the confirmability of the data is another critical concept emphasized in qualitative studies (Erlandson et al., 1993). They use the quotations of the participants in explaining the qualitative data to minimize the researchers' prejudices and strengthen the findings. 


\section{Findings}

In this section, case studies of three teachers and a comparison are given under separate headings. In this way, a general structure was attempted by explaining each teacher's case study in a narrative structure while crosscomparing them.

\section{Selma}

The Rope Activity was practiced in the lesson. The activity has four parts: a rope puzzle, four children, more rope puzzles, and design your rope puzzle. The teacher carried out the lesson in three phases. These phases are introduction, inquiry, and sharing of understanding. The teacher organized the class for group work, which were created as homogeneous in line with their achieving level, and explained the students' expectations for the introduction phase's implementation process. The teacher organized the activity settings for achievement diversity groups. The following quote is an example of teacher explanation in this stage. The quote [1] comes from classroom practice.

I do not want to follow a specific solution, okay? Everyone will try to find an answer using different ways. You can use an equation, practice, and trial-and-error method. It is your choice. You must shape the answer to a question to take into consideration each idea in class. Okay?

After the initiation phase, the teacher and students studied activity in inquiry phases. The teacher supported the students to accomplish the investigation process and did not respond to the students' idea as true or false. The teacher tried to realize their mistakes and oriented low achievement students to alternative solutions ways to achieve. This situation shows parallelism with the teacher's initiation explanation (quote 1) and the following interview quote. The following quote is from the interview.

Interviewer: Did you make anything to involve low achievement students in the activity process? Teacher: For example, I told them that they could predict rather than deal with addition extraction and equations. I told them they could virtually achieve something drawing. In this way, I guided them.

Lastly, all groups present their process and results in all classes in the sharing of understanding phases. The teacher encourages students to express their solution ways without judgment as true or false in this stage.

"...now, it does not matter whether the answer to the first question is correct or not. I wonder only what you thought, okay? Let us start with the first group and tell us how you solved it. You can tell on the board." [Classroom observation]

The teacher faced some critical challenges in the inquiry stage. Classes are very crowded, and students' achievements are not high, and it is difficult to know how each student can learn more quickly in crowded classrooms. The teacher says the following:

"I carried out this practice in groups, so high academic level students responded to questions, and low academic level students were more passive. Students' levels of understanding, their concerns and their abilities differ from each other due to individual differences. For example, someone can achieve it by music or drawing, so it is difficult to get involved in all of them. It is hard to learn how all of them understand more easily because the classes are very crowded.'[Interview]

As mentioned above, the teacher tries to manage the process by providing alternative learning processes for lowachieving students. Instead of answering students' explanations as true or false, the teacher encourages students to engage in activity and provides them with the opportunity to choose a method for the solution of the problem.

\section{Bülent}

The teacher carried out the IBL activity related to whether there is life on Mars for the CPD course reflection. The activity implementation consisted of three main stages, which was pointed out that in his' lesson evaluation form. These are namely 1) introduction (setting up groups, giving the problem situation to students) 2) inquiry 
(reading and thinking about problem situation, studying in groups), and 3) sharing of understanding (making a poster (optional) or present the group's work) [Evaluation form].

While the teacher was carrying out the activity to address achievement diversity in the steps given above, he focused on the following three strategies.

(1) The teacher set up groups that are heterogeneous in terms of achievement. According to the teacher, this strategy has advantages. The teacher says in this situation that "... homogenous groups cause a problem. Because, if all members of a group have low academic achievement, we cannot conclude at the end of activity", and "... heterogeneous groups addressing academic diversity compete in an undesirable competition. For this reason, group pressure on the successful student is increasing." [Interview]

(2) The teacher endeavoured that each in the group has a voice.

(3) The teacher provided opportunities for students to do peer teaching within the group. In this process, the teacher constructed different discussion groups. They investigated data and discussed to confirm whether there is life on Mars [Evaluation form]. They prepared their written arguments collaboratively in the process. After that, each in the group presented part of their arguments. The teacher managed the process in this way. The following quote was from the classroom observations when the students presented group ideas based on arguments.

“... Approximately $96 \%$ of the atmosphere is carbon dioxide, and the rest contains a small amount of argon, nitrogen and oxygen. There, thus, is not able to be life on Mars." [Classroom observation]

The teacher faced some critical challenges throughout the implementation. The first one comes from the achievement of diverse heterogeneous groups. High-achieving students became prominent and were made the leader in these groups. According to the teacher, if the classroom is not effectively managed, activity may not serve the purpose because the goal of the activity may not be available within a specific time. This problem comes from students not being familiar with group working. The teacher thinks that crucial challenges are to overcome with effective classroom management and that students adapt to the process. The following quote is from the interview for this situation.

Interviewer: Which situations do you have difficulty in the activity process?

Teacher: Classroom domination, time, and low cooperative study habits of students and time are a significant influence through the implementation process. It may not be sometimes possible that activity is carried out in 40 minutes. When students are given adequate knowledge, and if the classroom is managed effectively, it becomes useful. However, if there is a quarrel between two students, you have difficulties following the course plan or teaching.

\section{Ceren}

The general flow of the lesson is given to demonstrate how to use IBL when addressing achievement-related diversity. The teacher employed IBL activity related to renewable and non-renewable energy sources [Evaluation form]. The activity process consisted of three characteristic main stages. These are namely 1) introduction: Asking questions to get student attention and engage in the implementation process, 2) inquiry process: Students carry out an investigation and construct their argument, and 3) sharing of understanding.

Firstly, the teacher started the lesson by asking questions about the energy sources, which they learned for a few lessons to get the students' attention. For example, What are the sources of electric energy? Which criteria are used to prefer renewable and non-renewable energy sources? This section can be considered as the start of IBL. After this stage, the students were divided into heterogeneous groups considering their achieving level, carried out the inquiry process, constructed their argument, and persuaded each other in groups. The teacher paid attention to the heterogeneity of the groups and IBL to ensure diversity. She expresses this strategy, which she used in her answer to the interview questions.

"Ensuring that the groups are heterogeneous was one of the factors that I have taken care of in achievement-related diversity. I created the groups randomly. So, each group had students who were successful, intermediate, and low." 
In the inquiry process in order to support the diversity of success through the inquiry-based learning approach, the teacher "trying to increase student participation," "each student contributing according to his / her level of development" and "each student's goals are not at the same level" are indications that the teacher is successful in this sense. In particular, the teacher's response to the question about the contributions of IBL students supports this situation.

"IBL leads to all students working together. For this purpose, I am already using high-achieving and low-achieving students for the inclusion of students at all levels (without actually making such a distinction). As long as all of the students are included in the process, perhaps not all of them achieved at the same level, but they all have an acquisition related to a topic. The size of this may be larger for some students and less for some students. Anyway, my expectations are not the same. I evaluate them according to their current capacity and level."

In the section of sharing the understanding, the students presented their views in mutual groups for about 20 minutes. Not only the teacher, but also the student took the teacher's role when she decided who accepts the following turn-taking is a remarkable class observation regarding students' participation. Ceren had previously done activities related to inquiry-based learning, and the in-class norm was established within the class, especially in the sharing of understanding section. The teacher does not participate in these interactions unless the students ask for the guidance of the teacher. The teacher takes the floor to summarize the general understanding and targeted scientific concept at the end of this section. The next class observation note explains this.

\footnotetext{
"Students discuss the information they get in group discussions. Students present some arguments that will change their opinions in the course of the argumentation process. Some students in the group are more involved in the discussion. Nevertheless, even though some students participate more dynamically among the group, the group members allow each person to speak at least once; for example, one of the students has a warning to the other group member, 'Let Zeynep speak a little. Let talk"'. [Classroom observation]
}

During the observation period, Zeynep was one of the students who never spoke. The group members give the right to speak to a student who has no words to say something or to a student who has difficulty expressing herself. Thus, students encourage other members of the group to contribute at all levels to show how diversity is supported in the classroom.

The most challenging point for the teacher and the students in the practices was the students' expectancy related to this work, whether they would be graded by the teacher. The students believe that they are always graded in different practices in the classroom other than lectures. At the same time, whether they are graded or not affects their motivation and fear of making mistakes. Also, the students found it challenging to decide what they would write in their reflective diaries or the arguments they would present in group work because they were not sure what the teacher's expectation is. Ceren describes this situation as follows:

"Because the expectations of the children are always focused on a grade or score. I said that my expectation has just related to your participation regardless of any expected correct answer. I was mentioned that I wonder what you think about this course and what you learned, I added".

In terms of the main challenges in IBL, it is seen that the expectations of the education system in the Turkey are exam oriented. The teacher explains this situation as "the system [The teacher tries to explain that the Turkish education system has many exams to pass secondary school to high school and as well as high school to university. Besides that, every secondary school grade level has a national exam in every semester] leads us to exam-oriented teaching. When students have such an expectation, this makes it difficult for us to make IBL applications". In response to this situation and to meet the students' expectations, the teacher uses rubrics to solve these difficulties and thinks of it as a solution.

\section{Comparison of Selma, Bülent and Ceren}

First, even though the teachers carry out the lessons based on the same stages, there are some different strategies used by three teachers in the case study to address the diversity of success in their classrooms. Although these strategies differ, they show that teachers do not ignore the diversity of success in their classes. Consider these strategies in the context of inquiry-based learning. 
At the outset, while three teachers use the inquiry-based learning approach, they consider the students' differences in achievement. In the interviews and class observations, it was noted that the teachers formed heterogeneous groups in general. Especially in Bülent and Ceren's classes, this situation is seen. At the same time, Bülent and Ceren emphasized why they preferred the heterogeneous group rather than the homogenous one. For example, according to Bülent, "homogenous groups cause a problem. Because, if all members of a group are low in academic achievement, we cannot conclude at the end of activity". Selma also mentioned that a group work strategy was drawn on to accomplish the IBL activity. However, she said there was a problem related to the high and low academic students within group working. The trouble encountered by Selma is seen as a problem-related capacity of the class rather than homogeneity or heterogeneity of a group.

The teacher uses some strategies to support the low-level achievement student in different ways. On the one hand, Selma provides for students to determine the most convenient method for them. Besides that, she explicitly explains the new objectives to low-level students, and the teacher works with students as guidance. In this way, she addresses achievement-related diversity in the IBL methods, which explain the process. On the other hand, Ceren provides opportunities for students to do peer teaching and try to increase student participation. Bülent also endeavours to allow each student in the group a voice in the inquiry process. Furthermore, all of them guide the students to carry out an inquiry or to construct their argument. All the teachers have different problems in terms of critical challenges, such as not knowing the students' learning features, habits, expectations, crowded class, time, and exam-oriented teaching. The teachers try to overcome these challenges by effectively managing class, guiding, or using rubrics.

\section{Conclusion and Discussion}

As a result of interviews and in-class observations, it was determined that teachers used IBL by considering the diversity of success among students. In particular, it has been found that IBL is perceived and used as an approach that promotes student participation at all achievement levels. In parallel with this situation, it is considered that IBL both has a positive impact on knowledge acquisition, conceptual understanding and overcoming misconceptions (Gormally et al., 2009) and is a suitable approach to take into consideration diversity in classes (Brown, 2017; Miles \&Ainscow, 2010). It is also emphasized in the research that the students who fail, especially in the class, are an element that has to support participation in the class (Rivet \& Krajcik, 2004). The fact that teachers in the case study have different expectations from low and high-level students in IBL activities and the inclusion of all students in the group work are reflections of this situation.

It has been determined that some strategies to emphasize the diversity of success in IBL activities are prominent. Although these strategies are different, they enable inquiry-based learning to progress in the usual flow and enable them to address the diversity of success in the classroom. These strategies are presented in Figure 1. When Figure 1 is examined, it is seen that although the teachers have similar IBL processes, some use more of these strategies while others add different methods and try to engage all students. For the organization of heterogeneous groups in terms of the achieving levels for teamwork, although there are disagreements about how students should be organized in small group works, it is generally recommended to create heterogeneous ability in terms of their achieving level of the groups. It can be presented as evidence for teamwork in a heterogenous group that low-achieving students will be able to get assistance, encouragement, and stimulation from high-achieving students. In contrast, high-achieving students have a chance to enhance their cognitive abilities and presentation skills through interaction with low-achieving students (Cheng et al., 2008). A similar situation can be addressed in peer teaching. A meta-analysis study conducted by Lou et al. (1996) indicates parallel results: low-achieving students have a more effective process in heterogeneous than in homogeneous groups. In heterogeneous groups, although successful students seem to be more active, giving students the right to speak is one of the salient results. The teachers try to increase student's participation and allow that each in the group has a voice. For these situations, on the one hand, classroom dialogues contain interactive teaching and dialogic learning allows students to talk about some issues which affect their learning (EC, 2015).

On the other hand, Lack, Swars, and Meyers (2014) reported that academically low-performing students tend to avoid taking turns in interaction, taking a leadership role, and seeking explanations from their high performing peers in their study. Thus, the teacher's effective contribution in facilitating discourse provides opportunities for low-performing students to engage in discourse and contribute effectively for students with a low contribution (Empson, 2003). For this study, it can be said that the teachers' strategies in the IBL approach affect the formation of classroom norms and facilitate the students to engage in discourse. 


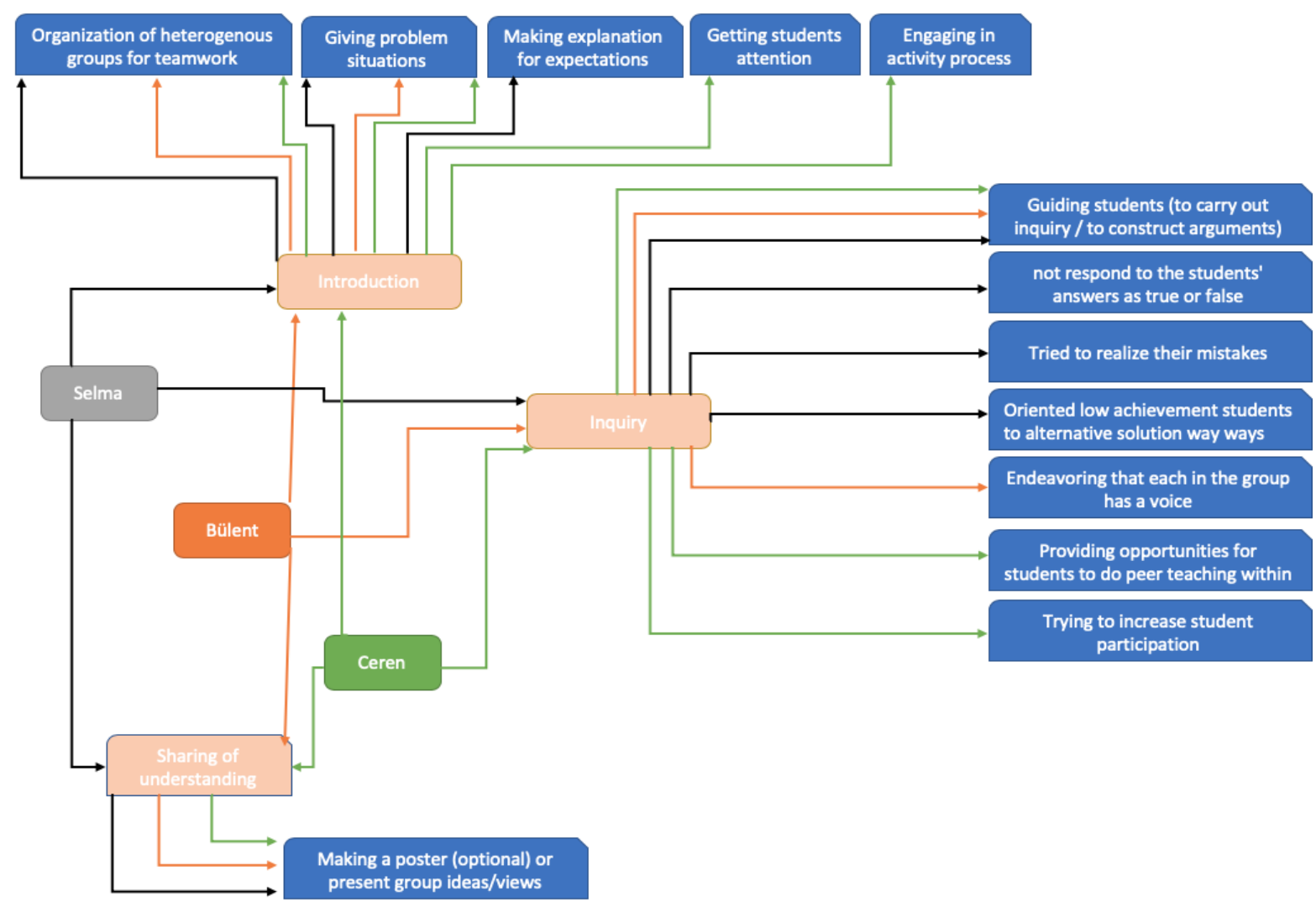

Figure 1. The general structure of IBL implementation of the teaches

Additionally, to support the diversity of success in the inquiry-based learning approach, the teachers try to increase student participation; this situation has parallels with other research results. Since research (e.g., Baxter, Woodward, \& Olson, 2001; Lubienski, 2000) points out when a teacher does not try to facilitate the discussion of topic content (mathematics), low-performing students do not have nearly any opportunities to make fruitful contributions to the group. Therefore, it can be clearly said that the teachers give all students changes to engage in the process. All teachers guide the students, especially low achievement students, to carry out the inquiry or construct their argument. In this process, one teacher does not respond to the students' answers as true or false. This strategy shifts further interaction from triadic interaction (initiation-respond-evaluation) to chain interaction (initiation-respond-feedback...) (Mortimer \& Scoot, 2003). In this way, students are enabled to interact with both the teacher and each other, and they have opportunities to realize their mistakes in the process. In the interaction, the teachers understand that the students cannot make inquiries; the teacher orients students to alternative solution ways, which are possible ways appropriate to the student's level. In other words, the teachers organize classroom activities for each student contributing according to their level of development. According to Lack et al. (2014), to affect student acquisitions positively, specifically assigning tasks related to the competence of low-performing students is one solution for low-status children. Therefore, it can be considered that the teachers are successful in terms of addressing achievement-related diversity in this sense.

The lack of a wide variety of strategies used by teachers can be seen as one of the crucial problems in case studies. In particular, the use of methods that will lead to better use of time in the classroom by using out of group work and evaluating it for successful diversity may appear to be an improvement in terms of achieving the desired goals. For instance, Meijier (2010) proposed that cooperative teaching, cooperative learning, collaborative problem-solving, heterogeneous grouping and alternative ways of learning approaches appear to be effective ways of dealing with diversity in school.

Unlike the other courses in terms of success in teachers' IBL activities, differentiation of expectations for each student or students at different levels may be considered concrete research evidence. This is achieved by conducting studies on similar IBL activities by determining how similar the most important one is from the student's current position. However, it is seen that the main problems are crowded classes and issues of the time. This situation shows itself as the most common problem in IBL activities. Besides, nationally-oriented, examoriented teaching has been seen as a situation that reduces teachers' use preferences, in particular with IBL. 


\section{Scientific Ethics Declaration}

We, the authors, declare that the scientific ethical and legal responsibility of this article published in JESEH journal belongs to the authors.

\section{Acknowledgements}

The project MaSDiV received funding from the European Union Erasmus + Programme under grant agreement no. 582943-EPP-1-2016-2-DE-EPPKA3-PI-POLICY. This paper reflects only the authors' views and the European Union is not liable for any use that may be made of the information contained herein.

\section{References}

Amaral, O., Garrison, L., \& Klentschy, M. (2002). Helping English learners increase achievement through inquiry-based science instruction. Bilingual Research Journal, 26(2), 213-239. https://doi.org/10.1080/15235882.2002.10668709.

Baxter, J., Woodward, J., \& Olson, D. (2001). Effects of reform-based mathematics instruction on low achievers in five third-grade classrooms. Elementary School Journal, 101(5), $529 \quad-547$. https://doi.org/10.1086/499686

Booth, T. \& Ainscow, M. (2002). Index for inclusion - developing learning and participation in schools. CSIE. http://www.eenet.org.uk/resources/docs/Index\%20English.pdf

Brown, J. C. (2017). A metasynthesis of the complementarity of culturally responsive and inquiry-based science education in K-12 settings: Implications for advancing equitable science teaching and learning. Journal of Research in Science Teaching, 54(9), 1143-1173. https://doi.org/10.1002/tea.21401.

Cheng, R. W. Y., Lam, S. F., \& Chan, J. C. Y. (2008). When high achievers and low achievers work in the same group: The roles of group heterogeneity and processes in project-based learning. British Journal of Educational Psychology, 78(2), 205. https://doi.org/10.1348/000709907X218160.

Chin, C., \& Chia, L. (2006). Problem-based learning: using ill-structured problems in biology project work. Science \& Education, 90(1), 44-67. https://doi.org/10.1002/sce.20097

Colburn, A. (2000). An inquiry primer. Science Scope, 23(6), 42-44.

Creswell, J. (2009). Research design: Qualitative, quantitative, and mixed methods approaches. Sage.

Doğan, Y. (2010). Fen ve teknoloji dersi programının uygulanması sürecinde karşılaşılan sorunlar [The problems encountered during the implementation of science and technology curriculum]. Van Yuzuncu Yil University Journal of Education, 7(1), 86-106.

EC [European Commission, DG Education and Culture] (2011). Progress towards the common European objectives in education and training, Indicators and benchmarks. Brussels.

EC [European Commission, DG Education and Culture] (2015). Education \& Training 2020, Schools policy, A whole-school approach to tackling early school leaving. Brussels.

EC [European Commission] (2013). Investing in Children: Breaking the cycle of disadvantage, Recommendations. Brussels.

Empson, S. B. (2003). Low-performing students and teaching fractions for understanding: An interactional analysis. Journal for Research in Mathematics Education, 34(4), 305-343. https://doi.org/10.2307/30034786.

ERG (2018). Eğitim izleme raporu 2017-18 [Education monitoring report 2017-18]. http://www.egitimreformugirisimi.org/wp-content/uploads/2017/03/EIR_2017_2018_29.11.18.pdf

Erlandson, D. A., Harris, E. L., Skipper, B. L., \& Allen, S. T. (1993). Doing naturalistic inquiry: A guide to methods. Sage.

Eurydice (2019). Turkey overview. Retrieved from: https://eacea.ec.europa.eu/nationalpolicies/eurydice/content/turkey_en.

González, J., \& Wagenaar, R. (Eds.). (2003). Tuning educational structures in Europe. University of Deusto.

Gormally, C., Brickman, P., Hallar, B., \& Armstrong, N. (2009). Effects of inquiry-based learning on students' science literacy skills and confidence. International Journal for the Scholarship of Teaching and Learning (3)2, Article 16. https://doi.org/10.20429/ijsotl.2009.030216.

Hassard, J. \& Dias, M. (2009). The art of teaching science: Inquiry and innovation in middle school and high school. Routledge

Kaya, G., \& Yllmaz, S. (2016). The impact of open inquiry based learning on students' achievement and development of science process skills. Hacettepe University Journal of Education, 31(2), 300-318. https://doi.org/10.16986/HUJE.2016016811. 
Lack, B., Swars, S. L., \& Meyers, B. (2014). Low- and high-achieving sixth-grade students' access to participation during mathematics discourse. The Elementary School Journal, 115(1), 97-123. https://doi.org/10.1086/676947.

Lan, S.-W., \& de Oliveira, L. C. (2019). English language learners' participation in the discourse of a multilingual science classroom. International Journal of Science Education, 41(9), 1246-1270. https://doi.org/10.1080/09500693.2019.1607618.

Larina, G. \& Markina, V. (2019). Hidden mechanisms of differentiation: teachers' beliefs about student diversity. Journal for Mathematics Teacher Education. https://doi.org/10.1007/s10857-019-09436-1.

Lincoln, Y. S. \& Guba, E. (1986). Research, evaluation and policy analysis: heuristics and disciplined inquiry. Review of Policy Research, 5(3), 546-565. https://doi.org/10.1111/j.1541-1338.1986.tb00429.x.

Lou, Y., Abrami, P. C., Spence, J. C., Poulsen, C., Chambers, B., \& d' Apolonia, S. (1996). Within-class grouping: A meta-analysis. Review of Educational Research, 66, 423-458. https://doi.org/10.2307/1170650.

Lubienski, S. T. (2000). A clash of social class cultures? Students' experiences in a discussion intensive seventh-grade mathematics classroom. Elementary School Journal, 100(4), 377- 403. https://doi.org/10.1086/499647.

MaSDiV. (2020). Rope. https://icse.eu/international-projects/masdiv/

Meijer, C. J. (2010). Special needs education in Europe: inclusive policies and practices. Journal of Inclusion, 4(2).

Miles, S., \& Ainscow, M. (Eds.). (2010). Responding to diversity in schools: An inquiry-based approach. Routledge.

Ministry of National Education [MoNE]. (2005). Illkögretim fen ve teknoloji dersi öğretim programı ve klavuzu [Elementary science and technology lesson curriculum and guide]. Ministry of National Education

Ministry of National Education [MoNE]. (2018). Fen bilimleri dersi ögretim programı [Science course curriculum]. Ministry of National Education

Minner, D., Levy, A., \& Century, J. (2010). Inquiry-based science instruction-what is it and does it matter? Results from a research synthesis years 1984 to 2002. Journal of Research in Science Teaching, 47(4), 474-496. https://doi.org/10.1002/tea.20347.

Mortimer, E. F., Scott, P., \& El-Hani, C. N. (2012). The heterogeneity of discourse in science classrooms: The conceptual profile approach. In Second international handbook of science education (pp. 231-246). Springer

Mortimer, E., \& Scott, P. (2003). Meaning-making in secondary science classrooms. McGraw-Hill Education.

Nasir, N. S., \& Cobb, P. (2006). Improving access to mathematics: diversity and equity in the classroom. Multicultural Education Series: ERIC.

OECD (2014). TALIS 2013 results: an international perspective on teaching and learning. OECD Publishing.

OECD (2019). PISA 2018 results (Volume I): what students know and can do. OECD Publishing. https://doi.org/10.1787/5f07c754-en.

Patton, M. Q. (1990). Qualitative evaluation and research methods. Sage.

Ramnarain, U. D. (2014). Teachers' perceptions of inquiry-based learning in urban, suburban, township and rural high schools: The context-specificity of science curriculum implementation in South Africa. Teaching and Teacher Education, 38, 65-75. https://doi.org/10.1016/j.tate.2013.11.003.

Republic of Turkey Ministry of Interior Directorate General of Migration Management (2019). Residence Permits.

Rivet, A., \& Krajcik, J. (2004). Achieving standards in urban systemic reform: An example of a sixth-grade project-based science curriculum. Journal of Research in Science Teaching, 41(7), 669-692. https://doi.org/10.1002/tea.20021.

Ryu, M. (2019). Mixing languages for science learning and participation: an examination of Korean-English bilingual learners in an after-school science-learning programme. International Journal of Science Education, 41(10), 1303-1323. https://doi.org/10.1080/09500693.2019.1605229.

Stake, R. E. (1995). The art of case study research. Sage.

Starcic, A. I. (2010). Educational technology for the inclusive classroom. Turkish Online Journal of Educational Technology-TOJET, 9(3), 26-37.

Taş, U. E., Arıcı, Ö., Ozarkan, H. B., \& Özgürlük, B. (2016). PISA 2015 ulusal raporu [PISA 2015 national report]. Ministry of National Education

TEDMEM. (2019). 2018 Eğitim değerlendirme raporu [2018 Educational Evaluation Report]. Türk Eğitim Derneği Yayınları.

Tüysüz, C \& Aydın, H. (2009). The elementary school science and technology teachers' perceptions toward to new science and technology curriculum. Journal of Gazi Educational Faculty Journal, 29(1) 37-54.

U.S. Department of Education. (2002). No Child Left Behind Act of 2001. U.S. Department of Education. https://www.ed.gov/offices/OESE/reference. 
Wilson, C., Taylor, J., Kowalski, S. Carlson, J. (2010). The relative effects and equity of inquiry-based and commonplace science teaching on students' knowledge, reasoning, and argumentation. Journal of Research in Science Teaching 47(3), 276-301. https://doi.org/10.1002/tea.20329.

Yin, R. K. (2009). Case study research: Design and method. Sage.

Yıldırım, A. \& Şimşek, H. (2016). Sosyal bilimlerde nitel araştırma yöntemleri [Qualitative research method in social sciences]. Seçkin Publishing

Yıldırım, H. H., Yıldırım, S., Yetişir, M. İ., \& Ceylan, E. (2013). PISA 2012 ulusal ön raporu [PISA 2012 national preliminary report]. Ministry of National Education.

\begin{tabular}{|c|c|}
\hline \multicolumn{2}{|c|}{ Author(s) Information } \\
\hline Gökhan Kaya & Metin Şardăg \\
\hline Kastamonu University & Van Yüzüncü Yill University \\
\hline Faculty of Education, Kastamonu, Turkey & Faculty of Education, Van, Turkey \\
\hline Contact e-mail: gkaya@kastamonu.edu.tr & ORCID iD: $\underline{0000-0003-2162-8289}$ \\
\hline ORCID iD: $\underline{0000-0003-4044-9243}$ & \\
\hline
\end{tabular}

